\title{
Fetal Medicine in India: Taking Stock of 2015, and Planning for 2016 at the Journal of Fetal Medicine
}

\author{
I. C. Verma ${ }^{1}$
}

Received: 5 February 2016/Accepted: 9 February 2016/Published online: 19 February 2016

(C) Society of Fetal Medicine 2016

Another year has gone by, and we at the Journal of Fetal Medicine (JFM) reflect over what we achieved in the past year, and outline what we plan to do next year. After editing the journal for the past 2 years, I am led to conclude that although excellent work is being carried out in fetal medicine in India, there is a dearth of submission of articles for the journal. The well-recognized experts, with busy practices, are preoccupied in giving lectures and demonstrations in various conferences, and have, therefore, little time to write. I have struggled to get good articles for publishing in the Journal. The task is made harder as this is a new Journal, and not yet indexed in Pubmed, although it is backed by one of the leading International publishing houses-Springer-and it appears in many abstracting databases. We have taken a number of steps to improve the situation in 2016.

In spite of these difficulties we have maintained a high standard of publication, which is largely due to our hardworking and capable Publication Editor, Nidhi Mehta, who reads through each word of the articles before they appear in print. The Journal is the official organ of the Society of Fetal Medicine. The Society has done a phenomenal job in organizing as many as 16 conferences and CMEs during the past year, bringing outstanding international experts to participate and interact with delegates. This has been mainly due to the untiring efforts of the able and energetic secretary, Ashok Khurana. The Society has succeeded admirably in its mission to open minds to fetal needs, and bring specialists from various fields such as obstetrics,

\section{C. Verma}

jfm200@yahoo.co.in; jfm200@gmail.com

1 Center of Medical Genetics, Sir Ganga Ram Hospital, Ranjinder Nagar, New Delhi 110060, India genetics, fetal medicine, ultrasound, radiology, pediatric surgery, etc. into its fold. The Society aims to facilitate rapid translation of research findings into clinical application, and conduct hands-on training in various imaging techniques, and publish guidelines for practice in ultrasound, fetal medicine, and genetic techniques and counseling. Chapters have been formed in 12 cities-Ludhiana, Patiala, Chandigarh, Panipat, Delhi, Bhubaneswar, Mumbai, Aurangabad, Jodhpur, Gurgaon, Faridkot, and Kochi. As announced by Ashok, all members receive a free copy of the issue as a pdf file. However, those members desiring a print copy will have to pay a subscription which is highly subsidized. Elsewhere in the Journal, you can look up the subscription form, fill, and send to us. As a special incentive, the first 100 members who enroll would be provided all the eight issues published so far at a special price of Rs. 1500 .

Last year, we had an outstanding issue on perinatal pathology, brilliantly edited by Raj Kapur from USA [1]. One of the authors who contributed to this issue told me that she enjoyed writing the article due to the very helpful suggestions made by the editor. The issue contains six articles covering how to perform a fetal autopsy [2], gross examination of the placenta [3], fetal thrombotic vasculopathy [4], placental mesenchymal dysplasia [5], examination of congenitally malformed heart [6], nonmmune hydrops [7] and fetal dysmorphology [8]. Other articles previously published on fetal autopsy are- "At least and infantogram" [9], and its usefulness in limb anomalies [10]. I urge all the members to read through these articles, as each of them is a gem, which will help them improve their knowledge of fetal medicine.

Use of noninvasive prenatal testing (NIPT) to screen for fetal aneuploidies has dominated the field for the past 2 years, and will continue to do so in the years to come. We 
had some exceptionally good articles in the previous issues on noninvasive prenatal diagnosis by Benn [11], Cuckle [12] and Greeley et al. [13]. Indian perspectives were also presented $[14,15]$. Although NIPT has a high sensitivity (over $99 \%$ ), it is still classified as a screening test and positive results need confirmation by amniocentesis or by some other tests on fetal tissues. However, it has led to a remarkable reduction in the number of amniocenteses and chorionic villus samplings. Its use remains restricted to screen high-risk pregnancies, as its utility in low-risk women remains to be validated in a larger number of samples. It is most commonly used as contingent test after the combined test-first trimester screening using nuchal translucency (NT) scan and biochemical test by assay of PAPP-A and free $\beta$-hCG. However, the use of combined test has many advantages which cannot be provided by NIPT alone. Therefore, the first trimester combined screening (using NT and biochemical tests) is there to stay. Many avoid doing NIPT if the NT is more than 95 centile for the CRL, as it has many causes beyond aneuploidies, which cannot be currently detected by NIPT, and require fetal DNA.

The NIPT has been extended to detecting microdeletions, which have a combined frequency of 1 in 167 pregnancies [16]. Since microdeletions are not related to maternal age, in younger women, their frequency may equal or exceed that of Down syndrome. This has led some authors to suggest that every sample of fetal tissue (CVS or amniotic fluid) should be tested for microdeletions through use of microarrays. This cannot yet be recommended in India, primarily for two reasons-lack of expertise in the interpretation of copy number variations (CNVs) observed, and the cost of the microarrays. The use of massively parallel sequencing (MPS) is likely to extend testing for microdeletions to all the 24 chromosomes, and is also beginning to be applied to diagnosis of single gene disorders.

As a corollary to the above, some authors suggest that very pregnant women need genetic counseling [17]. Abroad, much of this work is carried out by the genetic counselors. There are few geneticists and even fewer genetic counselors in India at present. It is good that at many places courses in genetic counseling have been started (Hyderabad, Bangalore, Manipal, Mumbai, Chandigarh, etc.). These trained counselors will fill the void, and will be able to provide pre-test and post-test counseling to the pregnant women.

One benefit of NIPT would be that it can be offered to pregnant women in peripheral areas as only venous blood is required for the studies, and specialized skills for sampling fetal tissues is not essential. Gundabattula and Fernandez [18] have described how they are taking fetal medicine to the rural areas. It is worth mentioning here the experiment conducted by Suresh in Chennai, in training the doctors in the peripheral rural areas in the use of ultrasound and interpretation of the images, and their monitoring through a central portal in Chennai. We are trying to get him to write this up for the Journal.

We published the guidelines developed by the Society of Fetal Medicine for anomaly scan in the second trimester [19]. In 2016 we plan to publish many more guidelines to help in the correct evaluation of fetal health. Suresh provided his own perspective on the anomaly scan in the second trimester-the rule of three [20]. Ratha and Khurana [21] describe how to record NT correctly, and the pitfalls. This short paper should be essential reading for all ultrasonologists. Experience shows that NT is not being measured properly at many places. The Society is conducting numerous courses for measuring NT correctly, and certifying those who take this course. However, more needs to be done in this direction, and this brings out the importance of the articles we publish as the written word can reach more people.

The article by Lall and colleagues [22] states that in their experience, "FISH is not suitable as a standalone test for detecting fetal chromosomal abnormalities". This reinforces the message that NIPT, which screens for abnormalities only in five chromosomes, and is thus analogous to FISH studies for aneuploidy, does not detect all chromosomal abnormalities and therefore, has to be used judiciously. The paper on prenatal diagnosis of lysosomal disorders by Sheth's group [23] highlights the availability of advanced biochemical prenatal tests in India.

In ultrasonography, most investigators are using the standards developed in the Western populations, and that also many years ago. Suskin and colleagues [24] reported ethnic difference in prefrontal space among blacks in USA, as compared with the "white population". In spite of the development of international standards in fetal growth [25], which were derived from an ideal, well-nourished group of women in different countries, many experts feel that it is better to have our own standards in India, as for example for hypoplastic nasal bone. Sharma and colleagues published standards for nasal bone in Indians, which were smaller than the Western standards [26]. However, these pertained to only women in the second trimester. We are pleased to publish the standards on length of nasal bone in India [27]. In cases with hypoplastic nasal bones, we have been able to avoid amniocentesis by using the Indian reference values. We plan to have an issue on "standards for ultrasound measurements among Indian patients". We urge all those who have significant data on this topic to publish their observations so that the void is filled soon.

In 2014, we published articles of practical utility on "growth restriction [28] and $\mathrm{Rh}$ iso-immunization [29]. The commonest single gene disorder in India is beta 
thalassemia, and the carrier frequency among various ethnic groups varies from 3 to $15 \%$. It is recommended that every woman should be screened for carrier status of beta thalassemia, although the precise method for this is under debate. If cost was not a consideration then HPLC for estimation of $\mathrm{Hb} \mathrm{A} 2$ would be the ideal method. However, keeping in mind the financial constraints, NESTROFT (naked eye single tube osmotic fragility test) has been suggested as a screening test. Mendiratta and colleagues [30] published their experience with this, although the expert commentary by Colah [31] suggested NESTROFT along with red cell indices to be a good alternative.

Amar Bhide and his colleagues from UK contribute "Journal watch" as a regular feature summarizing important articles from other journals [32], and Bijoy summarized the important presentations at the World Congress in Fetal Medicine in Greece [33]. We will continue to publish similar features in 2016.

In the past year there has been significant excitement in the field of fetal medicine. The National Institute of Health has invested \$46 million in the Human Placenta Project, an initiative to address key, unanswered questions about the placenta [34]. Recent improvements in ultrasound resolution and careful observations have led to the diagnosis of many structural anomalies in the first trimester. This can be achieved by direct visualization of the fetal anatomy, for example, in cases of anencephaly, exomphalos, and megacystis, or by focused assessment of specific fetal structures triggered by the finding of indirect signs, for example, increased NT in association with major cardiac defects and abnormal intracranial translucency (IT) in association with open spina bifida. Recently, Rabi Chaoui described a new sign of cleft lip and palate (CLP), the maxillary gap, which is visible in the mid-sagittal plane of the fetal face used routinely for measurement of NT thickness [35]. Our readers are urged to adopt these techniques into their practice, and identify malformations in the first trimester scan. However, it is well to remember that 'ultrasound is an invaluable third eye, but it can't see everything'. We get evidence of this every day, as many ultrasonologists do not evaluate NT correctly, others examine it and never write out the value and just say that it is "normal", while still others fail to diagnose important malformations until late in gestation. We are happy to have published how to obtain a good NT scan and avoid pitfalls [21]. We urge all ultrasonologists to read this article. This shows the task that lies ahead for the Society, to ensure that most ultrasonologists record the NT correctly, and diagnose malformations as early as possible in pregnancy.

An important report emanated from Brazil where Zika virus, transmitted by Aedes mosquitos (that also transmit dengue virus), has been associated with the birth of babies with microcephaly [36]. Of 35 infants born with microcephaly, the mothers of all 35 had lived in or visited Zika virus-affected areas during pregnancy, 25 (71\%) infants had severe microcephaly (head circumference $>3$ SD below the mean for sex and gestational age), and 17 (49\%) had at least one neurologic abnormality. Tests for other congenital infections were negative. Zika virus RNA was demonstrated by RT-PCR in the amniotic fluid samples from two pregnant women whose fetuses were found to have microcephaly by prenatal ultrasound. Zika virus was first identified in Uganda and then spread to Brazil, from where it has extended to 21 countries in South America, Caribbean, North America, and Europe [37]. This cautions us to always look out for an environmental cause if babies with similar malformations or defects are born in a particular area.

One of the bugbears of fetal medicine is the birth of preterm babies. A significant improvement in the survival of very preterm babies has been observed, with many without any handicaps. Two National Institute of Child Health and Human Development (NICHD)-supported studies showed the importance of teaching mothers how to interact with their preterm babies, and the benefits of milking of the cord which pushes blood through the umbilical cord into an infant's abdomen [38, 39]. It is clear that preterm birth (PTB) is a complex condition resulting from multiple etiologic pathways. There is a definite genetic component to the pathogenesis of PTB, as evidenced by twin studies, heritability studies, and investigations from large population databases. Although numerous single nucleotide polymorphisms (SNPs) have been associated with PTB, results have been inconsistent and overall disappointing. Recent genetic studies of spontaneous PTB have been reviewed by McPherson and Manuk [40].

We have exciting articles in the pipeline: symposia on fetal procedures, neural tube defects, intrauterine infections, biochemical screening during pregnancy, Doppler in obstetrics, counseling and prenatal diagnosis of common genetic disorders, guidelines on fetal safety from radiation, the first trimester anomaly scan, and imaging of fetal heart. Each of these topics will have a number of articles, and the first ones for fetal procedures and prenatal diagnosis of common genetic disorders appear in the January-March 2016 issue.

Given the advances in ultrasonography and molecular biology, the field of fetal medicine has entered a very exciting phase. We suggest you keep tuned to the JFM to keep up to date with the latest advances in this field, which you can immediately adopt in your practice. Happy reading and a happy new year.

\section{Compliance with ethical standards}

Conflict of interest The author has no conflict of interest for the matter included in this editorial. 


\section{References}

1. Kapur RP. Perinatal pathology and fetal medicine. J Fetal Med. 2015;2(3):99-100.

2. Jaiman S. Performing a perinatal autopsy. J Fetal Med. 2015;2(3):101-12.

3. Jaiman S. Gross examination of the placenta and its importance in evaluating an unexplained intrauterine demise. J Fetal Med. 2015;2(3):103-20.

4. Marsden L, Comstock J. Fatal thrombotic vasculopathy. J Fetal Med. 2015;2(3):121-6.

5. Ernst LM. Placental mesenchymal dysplasia. J Fetal Med. 2015;2(3):127-34.

6. Erickson LK. An approach to the examination of the fetal congenitally malformed heart at autopsy. $J$ Fetal Med. 2015;2(3):135-42.

7. Parks WT. A pathologists approach to non-immune hydrops. J Fetal Med. 2015;2(3):143-50.

8. Puri RD. Fetal dysmorphology. J Fetal Med. 2015;2(3):151-9.

9. Deka D, Naha M, Dadhwal V, Kabra M, Gupta N. At least an infantogram if not perinatal autopsy. $J$ Fetal Med. 2014;1(1):33-9.

10. Kotecha UH, Puri R, Dash P, Bijarnia-Mahay S, Lall M, Verma IC. Need for fetal autopsy and genetic diagnosis in fetal limb anomalies. J Fetal Med. 2014;1(3):151-7.

11. Benn P. Noninvasive prenatal testing using cell-free DNA in maternal circulation. J Fetal Med. 2014;1(3):107-11.

12. Cuckle H. Steering the course between optimal policies and practical restraints. J Fetal Med. 2014;1(1):3-5.

13. Greeley ET, Kessler KA, Vohra N. Clinical applications of noninvasive prenatal testing. J Fetal Med. 2015;2(1):11-7.

14. Verma IC. Noninvasive prenatal testing: the Indian perspective. J Fetal Med. 2014;1(3):113-8.

15. Dash P, Puri RD, Kotecha U, Bijarnia S, Lall M, Verma IC. Using noninvasive prenatal testing for aneuploidies in a developing country: lessons learnt. J Fetal Med. 2014;1(3):131-5.

16. Wapner RJ, Martin CL, Levy B, et al. Chromosomal microarray versus karyotyping for prenatal diagnosis. $\mathrm{N}$ Engl $\mathrm{J}$ Med. 2012;367:2175-84.

17. Evans MI, Andriole S, Evans SM. Genetics—an update on prenatal screening and diagnosis. Obstet Gynecol Clin N Am. 2015;42:193-208.

18. Gundabattula SR, Fernandez E. Taking fetal medicine to the community. J Fetal Med. 2014;1(3):119-21.

19. Khurana A, Makhija B, Deka D, Rama Murthy BS, Sachdev R, Chawla D, et al. Society of Fetal Medicine Practice guidelines for the second trimester anomalies scan. J Fetal Med. 2014;1(1):11-5.

20. Suresh S, Suresh I. The second trimester obstetric scan $(7+3=10)$ : a rational approach (including the "rule of three"). J Fetal Med. 2014;1(2):59-73.

21. Ratha C, Khurana A. "First things first": images for a proper nuchal translucency in the first trimester $11-13^{+6}$ weeks scan. J Fetal Med. 2014;1(2):55-7.

22. Lall M, Mahajan S, Saviour P, Paliwal P, Joshi A, Setia N, et al. FISH is not suitable as a standalone test for detecting fetal chromosomal abnormalities. J Fetal Med. 2015;2(2):53-9.
23. Sheth J, Mistri M, Sheth F, Datar C, Godbole K, Kamate M, et al. Prenatal diagnosis of lysosomal Storage disorders by enzyme study using chorionic villus and amniotic fluid. J Fetal Med. 2014;1(1):17-24.

24. Suskin B, Roe A-M, Bajaj K. Utility of prefrontal space ratio to screen for trisomy 21 in a racially diverse population: a pilot study. J Fetal Med. 2014;1(1):25-8.

25. Papageorghiou AT, Ohuma EO, Altman DG, Todros T, Cheikh Ismail L, Lambert A, et al. International Fetal and Newborn Growth Consortium for the 21st Century (INTERGROWTH21st). International standards for fetal growth based on serial ultrasound measurements: the Fetal Growth Longitudinal Study of the INTERGROWTH-21st Project. Lancet. 2014;384:869-79.

26. Sharma A, Tayal T, Narayani BH, Radhakrishnan P, Kaul A. Nasal bone length: the long and short of it. Evaluation of the reference values for the fetal nasal bone length at 16 to 25 weeks of gestational age in an Indian population. Prenat Diagn. 2013;33:800-3.

27. Kashikar SV, Lakhkar BN. Assessment of fetal nasal bone length and nasofrontal angle in the second trimester in normal Indian pregnancies. J Fetal Med. 2014;1(3):137-41.

28. Gujral K, Nayar S. Current trends in management of fetal growth restriction. J Fetal Med. 2014;1(3):125-9.

29. Agarwal K, Rana A, Ravi AK. Treatment and prevention of Rh Isoimmunization. J Fetal Med. 2014;1(2):81-8.

30. Mendiratta SL, Bajaj S, Popli S, Singh S. Screening of women in the antenatal period for thalassemia carrier status: comparison of NESTROFT, red cell indices, and HPLC analysis. J Fetal Med. 2015;2(1):21-5.

31. Colah RB. The use of NESTROFT for screening pregnant women for detection of $\beta$-thalassemia carriers. $J$ Fetal Med. 2015;2(1):9-10.

32. Scala C, Bhide A. Journal watch. J Fetal Med. 2015;2(2):51-2.

33. Balakrishnan BK. Report on the 13th World Congress in Fetal Medicine. Nice J Fetal Med. 2014;1(2):75-80.

34. Placenta NIH invests $\$ 46$ million in technologies to monitor placental health. NICHD News Release (2015).

35. Chaoui R, Orosz G, Heling KS, Sarut-lopez A, Nicolaides KH. Maxillary gap at 11-13 weeks' gestation: marker of cleft lip and palate. Ultrasound Obstet Gynecol. 2015;46:665-9.

36. Schuler-Faccini L, Ribeiro EM, Feitosa IM et al. Possible association between Zika virus infection and microcephaly-Brazil, 2015. MMWR Morb Mortal Wkly Rep 2016;65(Early Release):1-4. doi:10.15585/mmwr.mm6503e2er.

37. Hindustan Times, 28 January 2016. p 1+. http://paper.hindus tantimes.com/epaper/viewer.aspx

38. White-Traut RC, Rankin KM, Yoder JC, Liu L, Vasa R, Geraldo $\mathrm{V}$, et al. Influence of H-HOPE intervention for premature infants on growth, feeding progression and length of stay during initial hospitalization. J Perinatol. 2015;35:636-41.

39. Katheria AC, Truong G, Cousins L, Oshiro B, Finer NN. Umbilical cord milking versus delayed cord clamping in preterm infants. Pediatrics. 2015;136(1):61-9.

40. McPherson JA, Manuck TA. Genomics of preterm birth-evidence of association and evolving Investigations. Am J Perinatol. 2016 Jan 22. (Epub ahead of print). 